\title{
CRIANÇAS, FABRICAÇÃO DO ABANO E SABERES CULTURAIS DA COMUNIDADE DE ARAUÁ DA AMAZÔNIA BRAGANTINA
}

\section{CHILDREN, ABANO MANUFACTURING AND CULTURAL KNOWLEDGE OF ARAUÁ COMMUNITY OF BRAZANTINE AMAZON}

\author{
Marisa Martins Cardoso ${ }^{1}$ \\ Ana Paula Vieira e Souza ${ }^{2}$ \\ Rodrigo Fraga Garvão ${ }^{3}$
}

\begin{abstract}
Resumo: A pesquisa tem foco nos saberes cultural de crianças a respeito da fabricação do abano presente na Comunidade de Arauá, Polo Cacoal, Município de Bragança, Estado do Pará. O estudo busca identificar os saberes transmitidos pelos adultos da Comunidade de Arauá às crianças a respeito da confecção do abano. Os resultados revelam que existe um consenso sobre a existência de saberes tradicionais relacionados ao fabrico do abano. Para elas o abano tem um sentido e significado porque serve para abanar o fogo e manter a brasa, não é qualquer palha que serve para confeccionar o abano, é preciso saber tracejar e formar o losango. Ainda, outras questões encontradas no decorrer da pesquisa como o uso do abano para ensinar a Matemática às crianças no processo educativo. Conclui-se, que as técnicas utilizadas na fabricação do abano com relação aos saberes culturais da Comunidade não estão presentes no currículo escolar da Comunidade, por isso deve a escola valorizar uma proposta curricular, a fim de promover o ensino interdisciplinar, por exemplo, trabalhar a Etnomatemática pela Geometria no processo de alfabetização de crianças e valorizar os saberes culturais transmitidos entre gerações.
\end{abstract}

Palavras-chave: Crianças, Fabricação do Abano, Saberes culturais.

\begin{abstract}
The research focuses on the cultural knowledge of children regarding the manufacture of the fan present in Arauá Community, Polo Cacoal, Bragança Municipality, State of Pará. The study seeks to identify the knowledge transmitted by adults from Arauá Community to children regarding the making of the fan. The results show that there is a consensus on the existence of traditional knowledge related to the manufacture of the fan. For them the fan has a meaning and meaning because it serves to fan the fire and keep the embers, not just any straw that
\end{abstract}

\footnotetext{
${ }^{1}$ Acadêmica do Curso de Especialização da Universidade Federal do Pará. Professora colaboradora da Secretaria de Educação do Município de Bragança.

${ }^{2}$ Doutora em Educação e Professora da Universidade Federal do Pará, da Pós-Graduação em Linguagens e Saberes da Amazônia do Campus Universitário de Bragança. Membro do Grupo de Estudos e Pesquisa sobre Trabalho e Educação (GEPTE), coordenadora da Sessão Trabalho e Infâncias/UFPA. paulladesa@ufpa.br.

${ }^{3}$ Mestre em Desenvolvimento e Meio Ambiente urbano pela universidade da Amazônia (UNAMA), Professor da Universidade Federal Rural da Amazônia (UFRA), email:rodrigofragabh@gmail.com
} 
serves to make the fan, you need to know how to trace and form the rhombus. Still, other issues found during the research such as the use of the fan to teach mathematics to children in the educational process. It is concluded that the techniques is used in the making of the fan with respect to the cultural knowledge of the Community and are not present in the Community school curriculum, so the school should value a curricular proposal, in order to promote interdisciplinary teaching. For example, to work Ethnomathematics by Geometry in the process of literacy of children and to value the cultural knowledge transmitted between generations.

Keywords: Children, Abano Manufacturing, Cultural knowledge.

\section{Introdução}

Pesquisar os saberes culturais de criança a respeito da confecção do abano pelas suas vivências e de seus familiares na Comunidade de Aruá é o objeto de estudo. A área da pesquisa é o contexto do Campo do Município de Bragança, um território sociocultural carregado de saberes tradicionais da população local, que proporciona as crianças experiências de aprender e de auto-organização do trabalho coletivo no fabrico do abano.

A pesquisa assume, o conceito de Povos e Comunidades Tradicionais como conjunto de pessoas moradoras de uma área territorial, como "grupos culturalmente diferenciados e que se reconhecem [...], formas próprias de organização social”, de pertencimento da territorialidade no uso dos "recursos naturais como condição para sua reprodução cultural, social, religiosa, ancestral e econômica utilizando conhecimentos, inovações e práticas gerados e transmitidos pela tradição" e pelo trabalho (BRASIL, 2007, p. 137). O trabalho como modo coletivo de organização social da vida, a territorialidade carregada de interesses e conhecimentos (linguagem, crença, moradia etc.), uma identidade.

As características marcantes das culturas tradicionais como saber cultural tem relação com "o conhecimento aprofundamento da natureza e de seus ciclos que se reflete na elaboração de estratégias de uso de manejo dos recursos naturais. Esse conhecimento é transferido de geração em geração por via oral". São as experiências vivenciadas na comunidade e ensinadas nas interações sociais entre adultos e crianças (DIERGUES, 2002, p. 89). O povo tradicional assume uma identidade, um saber transmitido por meio de experiências entre fases geracionais, adultos, juventudes e crianças.

As experiências das pessoas mais velhas são traduzidas como uma informação 
usada "para definir aquilo que seus semelhantes veem, sentem, pensam, imaginam etc.", tem um sentido de saberes culturais transferidos de geração a geração por experiências do adulto para as crianças (GEERTZ, 1997, p. 87).

Assim, as crianças são produtoras de culturas infantis por meio do brincar e de brincadeiras na concepção de Souza (2018), para a autora elas apreendem o mundo do adulto e a sua volta de forma prazerosa pelos brincares. Nos brincares a criança encontra formas de interagir, aprender, internalizar a cultura por meio das interações no seu campo social. Elas desenvolvem o saber no contato com crianças e adultos. O brincar propicia o desenvolvimento da autonomia, da identidade e potencializa o processo de assimilação do conhecimento de crianças.

Epistemologicamente este estudo se insere na área da Etnografia no campo da interculturalidade que privilegia os saberes dos sujeitos em relação com o modo de vida e o respeito aos saberes culturais de crianças pertencentes à Comunidade Tradicional e dos próprios moradores que interagem com elas na confecção do abano, conforme mostra a imagem na figura 1, em que uma criança observa e aprende acerca da palha, dos tracejados e do fabrico do abano.

Figura 1. Criança observa os pais a traçar a palha para confeccionar o abano.

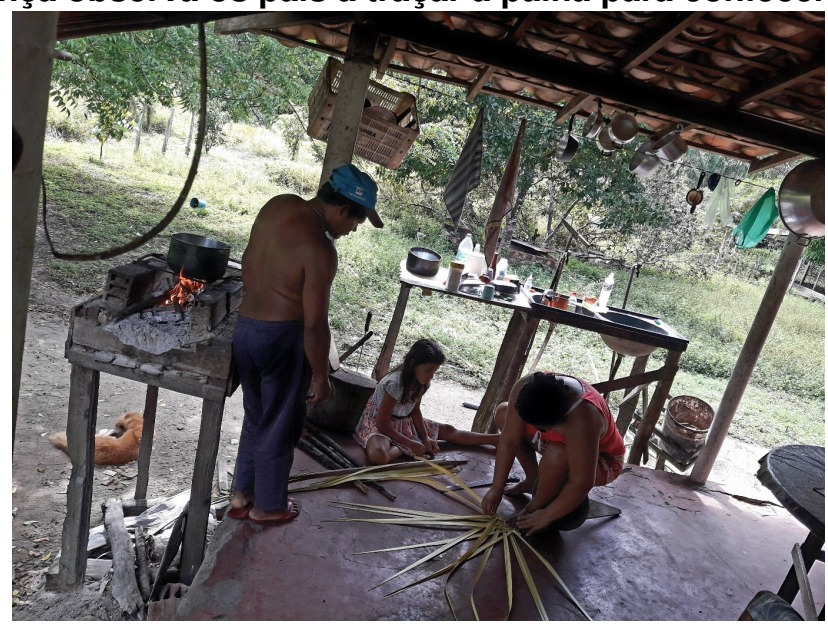

Fonte: Martins, 2019

Etnograficamente, a figura mostra aspectos do dia a dia da família na Comunidade do Arauá, pois ao observar os costumes, as manifestações de suas atividades sobre o abano, a fotografia revela um cenário característico do campo, por exemplo, fogão a lenha, cesto de palha, as árvores, animais, a casa de palha, a cozinha aberta, sem 
parede, além de outros elementos. A Etnofotografia como recurso de conhecimento na área da Educação Intercultural (TIBALLI; JORGE, 2007). Assim como a etnografia busca estudar a vida de pessoas, os costumes, as crenças e as tradições de uma sociedade, transmitidas de geração para geração e que permitem a continuidade ou modificação de uma determinada cultura de um sistema social.

Na Comunidade de Arauá é possível vivenciar a presença de crianças cotidianamente nas práticas do fabrico do abano pelo adulto. Além da criança observar os pais, avós na confecção do abano, elas aprendem o tracejado, o modo como as palhas entrelaçadas formam um losango, conforme mostra a figura 2. A produção desse elemento cultural tem a presença marcante de crianças na atividade do adulto.

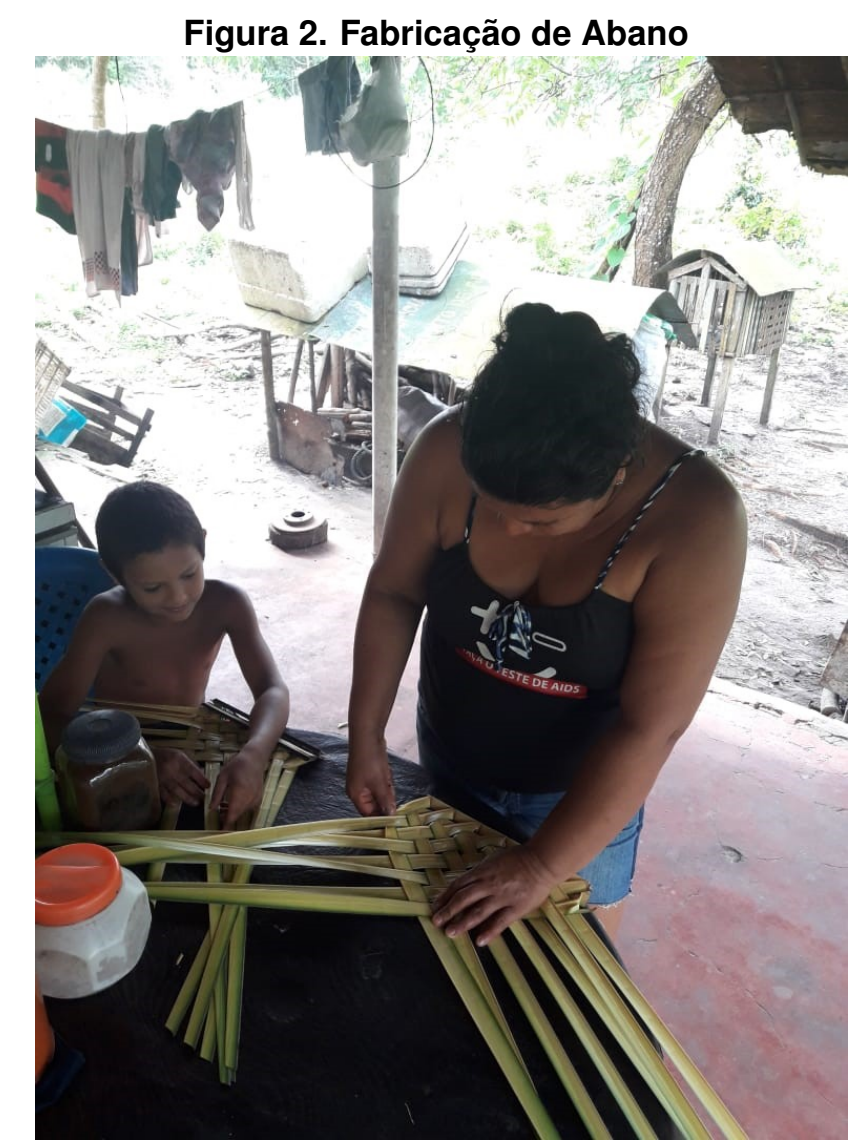

Fonte: Martins, 2019

O abano como artefato cultural tem um sentido para as crianças e para a população da Comunidade de Arauá, usado com frequência para abanar o fogo, manter aceso as labaredas do fogão de barro. É possível observar que os saberes culturais na confecção do abano têm relação com o processo de transmissão desse saber pelo traçado e a 
forma utilizada pelos adultos para ensinar a atividade às crianças e como a palha serve para o fabrico de cestos, paneiro, chapéus etc.

Os trançados do paneiro são produzidos pelos Wayana-Apalai, uma tribo do Norte do Pará, que "no contexto social, a cestaria, como outras categorias artesanais, constitui uma das formas de expressão da especialização artesanal, assim como da divisão sexual do trabalho, formas que são próprias da sociedade Wayana" (VELTHEM, 1998, p. 23). Os indígenas são povos que utilizam essa tecnologia do trançado na produção de cestos, peneiras, abanos e outros artefatos utilizados nas atividades da pesca, caça, agricultura e rituais religiosos. Ainda, os cestos são utilizados pelas mulheres em suas atividades domésticas e de agricultura.

O traçado de palha é uma cultura praticada por comunidades tradicionais e caboclas do Estado do Pará, herança da cultura indígena, transmitida pela tradição oral, um conhecimento recriado de pai para filho, portanto com características culturais de uma atividade produzida em família. Assim, o artesanato paraense revela muito da identidade do povo da Amazônia paraense, pois "espelha o contexto cultural de seu povo, do homem da região amazônica, índio, caboclo, amazônida, e do seu meio ambiente: floresta, rio, animais, lendas, mitos [...]" (FRANCO, 1997, p. 12).

Tais evidencias não difere do contexto da utilização do traçado, especificamente a confecção do abano de palha do coqueiro babaçu na comunidade do Arauá no Município de Bragança. A utilização desse artefato ocorre na casa do ribeirinho, casa de farinha, entre outros espaços como elemento para abanar o fogo em quaisquer circunstâncias, mas principalmente para acender ou manter abrasado o fogo. A palmeira do coco, o coco babaçu recebe diversos nomes, como: coco-de-macaco, coco-de-palmeira, cocode-rosário, coco naiá, coco pindoba, curuá, palha branca e chega a alcançar 20 metros de alturas.

As crianças aprendem com os adultos a respeito da utilização das folhas de palmeira na confecção de abano que é transmitido de geração em geração não perde as características culturais da forma que os indígenas fazem até atualmente, sendo um instrumento cultural de saberes dos povos da Comunidade de Arauá. 


\section{1. ÁREA DE ESTUDO}

A Comunidade de Arauá (Figura 4), Polo Cacoal, a $10 \mathrm{~km}$ do Município de Bragança-PA, o seu acesso não é asfaltado, estrada de piçarra, que no inverno amazônico, tempo de chuvas na Região dos Caetés se torna difícil. A origem da Comunidade de Arauá é manifestada pelos relatos dos primeiros moradores desse local, como os Senhores Miguel Cardoso, Firmino Ribeiro e Gregório Pereira, para eles o nome tem procedência de duas tribos das etnias Tupi Guarani e Tupi Guaraná, habitantes da Região da Comunidade do Arauá.

Figura 3. Mapa localizando Bragança no Estado e a Comunidade do Arauá

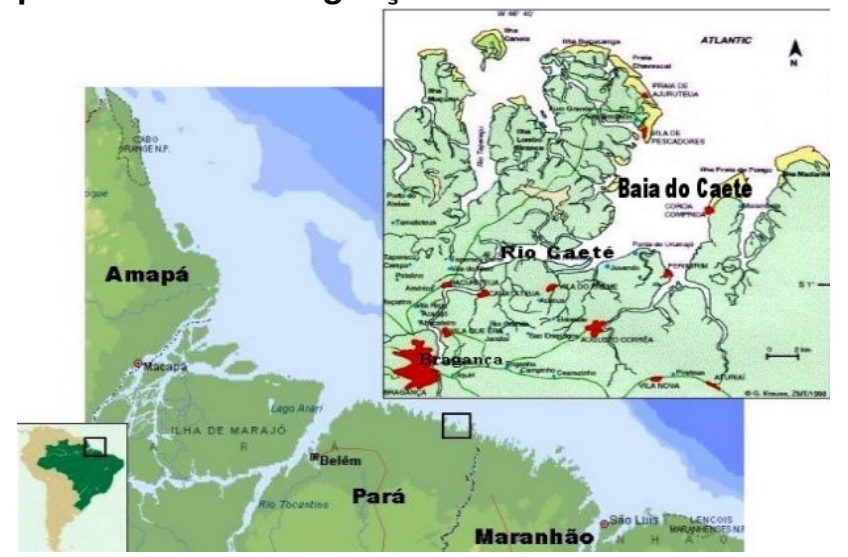

Fonte: Martins, 2019

Buscou-se pela memória coletiva ${ }^{4}$ de moradores a respeito da lenda sobre o nome Arauá, que na memória dos moradores foi transmitida entre gerações. Conta os moradores que alguns índios de uma dessas tribos saíram em busca de alimentos, descobriram uma árvore repleta de frutas vermelhas e decidiram não revelar a localização para outra tribo.

O índio pertencente a uma dessas tribos de nome Arauá desapareceu nessa respectiva árvore, nunca foi encontrado, o seu desaparecimento provoca desvelar o segredo mantido por anos, por isso, o local é chamado de Arauá (Figura 4).

A Comunidade de Arauá tem como tradição cultural a festividade de Nossa Senhora da Imaculada Conceição, comemorado no dia 08 de dezembro, padroeira.

\footnotetext{
${ }^{4}$ Conforme Halbewachs (1990, p. 51) "[...] cada memória individual é um ponto de vista sobre a memória coletiva, que pode muda conforme o lugar que ali eu ocupo, e que este lugar mesmo muda segundo as relações que mantenho com outros meios".
} 
Figura 4. Entrada do Arauá

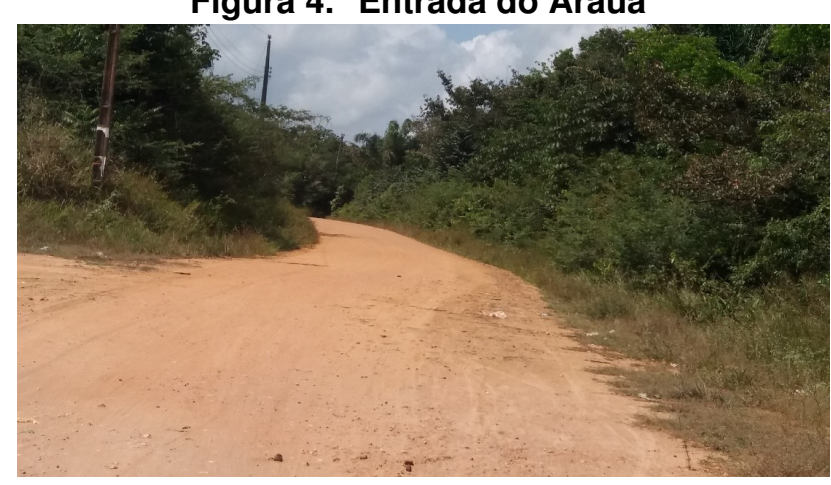

Fonte: Martins, 2019

Aproximadamente possui um quantitativo de 350 moradores, com casas nas proximidades do Rio Caeté, moradia de argila (barro) ou pau-a-pique, com a armação feita em madeira da mata do entorno, algumas habitações são cobertas com palhas, telhas de barro etc. algumas casas de alvenaria (Figura 5).

Figura 5. Habitação na comunidade de Arauá

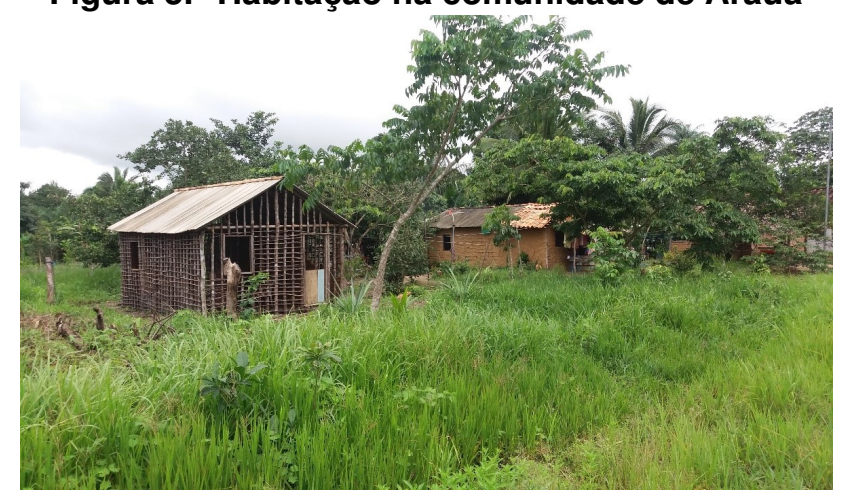

Fonte: Martins, 2019

A economia de subsistência é coleta do açaí (Figura 6), pesca artesanal realizada pelos pais de família, que utilizam a pesca para consumo próprio e para comercialização. Os adultos inserem as crianças nas suas atividades, para acompanhá-los e para aprenderem a prática cultural da Comunidade com o intuito de preservação dos saberes tradicional.

A escola ao desenvolver sua proposta pedagógica centrada no Meio Ambiente e Sustentabilidade buscar a realidade do fazer cotidiano das famílias e traz para o chão da escola o conhecimento vivido correlacionado com o conhecimento científico para a aprendizagem dos alunos. 
Figura 6. A colheita do açaí

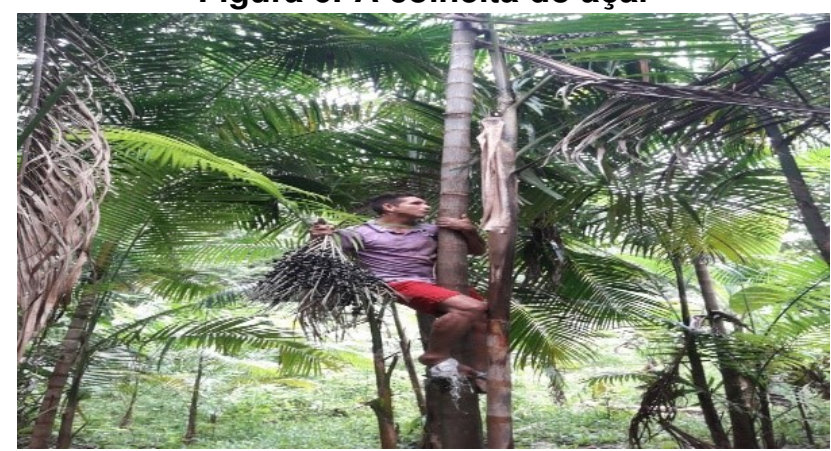

Fonte: Martins, 2019

No processo de subsistência econômica da Comunidade de Arauá se faz presente à produção da farinha na casa de forno e o forno ${ }^{5}$ (Figura 7) para fabricar o carvão. É uma atividade que exige habilidades de manuseio das mãos devido à extração de madeira da natureza para o fabrico do carvão.

Figura 7. Forno de fabricar carvão

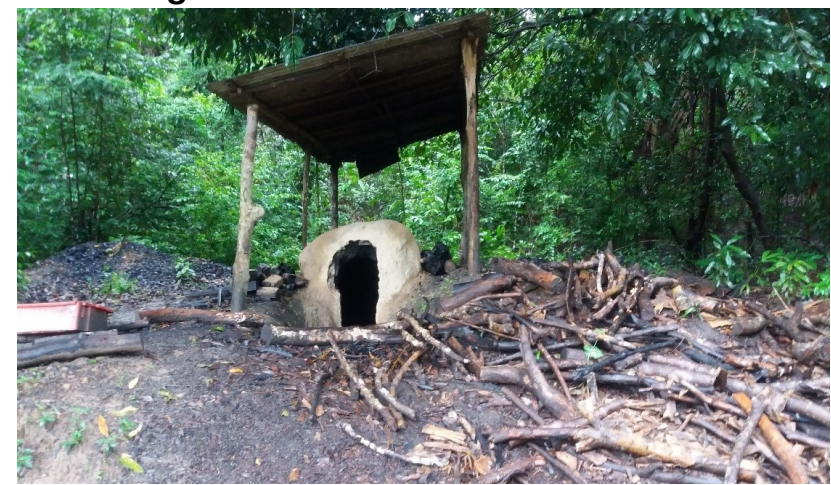

Fonte: Martins, 2019

Na casa da farinha (Figura 8), raramente, crianças realizam essa atividade, em alguns momentos as mulheres manuseiam o cabo do rodo.

A Escola da rede municipal (Figura 9) pertence ao contexto do campo definida a partir dos trabalhos desenvolvidos pelas famílias enquanto agricultores, extrativistas e pescadores e com proposta pedagógica para o socioambiental, tem buscado praticar um currículo focado na prática pedagógica de projeto, de base teórica em Freire, na perspectiva de educação humanizadora, a fim de diferir do currículo urbano.

\footnotetext{
${ }^{5}$ Uma masseira para receber a mandioca ralada, comprimida no tipiti e peneirada (um utensílio da tala de guarumã e o cabo de rodo para manipular e torrara a farinha, o rodo, geralmente, manipulado pelo homem).
} 
Figura 8. A casa de fabricar a farinha

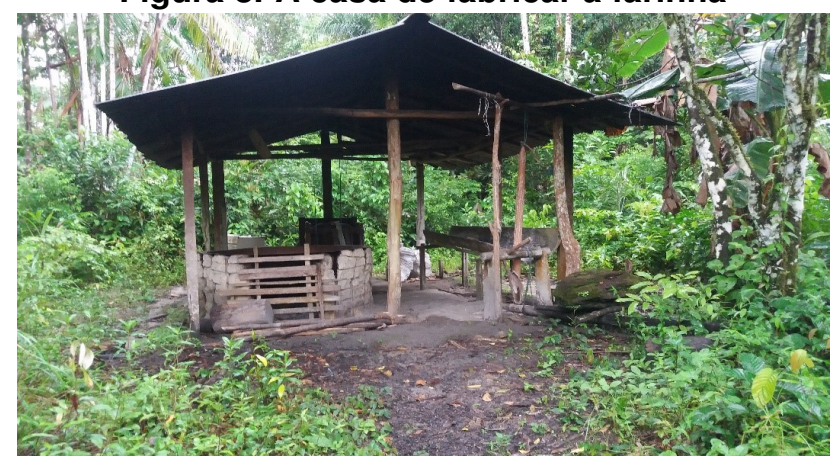

Fonte: Martins, 2019

Figura 9. Escola de Arauá

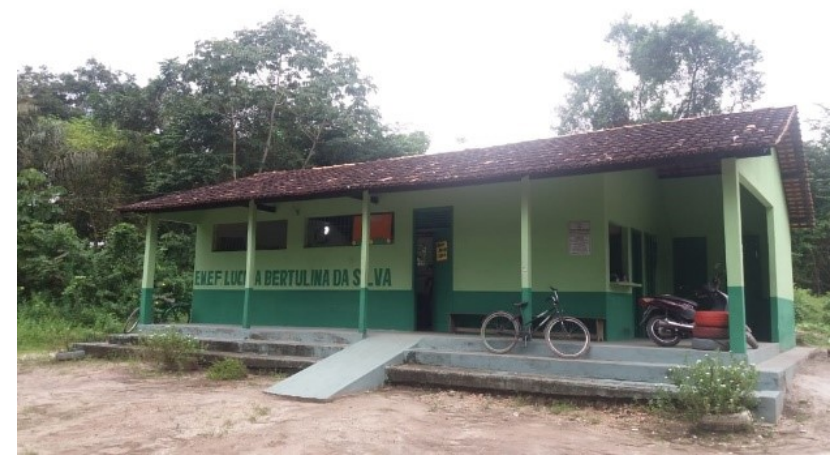

Fonte: Martins, 2019

A Escola da Comunidade de Arauá tem buscado pedagogicamente valorizar a dinâmica da vivência das crianças na valorização dos saberes culturais que trazem na sua bagagem cultural, ou seja, as experiências sociais do seu contexto familiar. Todavia, atende crianças em Classes Multisseriadas, ou seja, faixa etária diferente e ano; $1^{\circ}, 2^{\circ} \mathrm{e}$ $3^{\circ}$ e $4^{\circ}$ e $5^{\circ}$ ano no turno manhã e tarde.

As crianças de Arauá estão em constante relação com a natureza, seja para aprender a confecção dos artefatos culturais ou que signifique fabricar os próprios brinquedos com os elementos naturais, conforme mostra a figura 10. Na figura 10 as infâncias de Arauá confeccionam brinquedos usando o coco, a palha do coco, a madeira, os gravetos, entre outros elementos. Os brincares estão relacionados ao contexto cultural da floresta. Criam e recriam o brincar de bola no uso da palha e a trave com o coco, os gravetos servem de hastes.

No cenário de observação da Etnofotografia a presença se faz notar em função do instrumental, do observado pelo fotógrafo da intenção em mostrar o ambiente favorá- 
vel para o brincar de crianças no contexto do campo, que se diferencia do urbano, por exemplo, as crianças estão em volta do natural, da exuberância da floresta, próximas as aves etc. Elas se diferenciam pela liberdade de brincar, o de vivenciar uma infância livre do consumo, da mídia, da televisão.

No enquadrar da fotografia, o observado tem relevância ao se perceber a dinâmica do comportamento social das crianças para detalhar o aspecto cultural do brincar com a natureza.

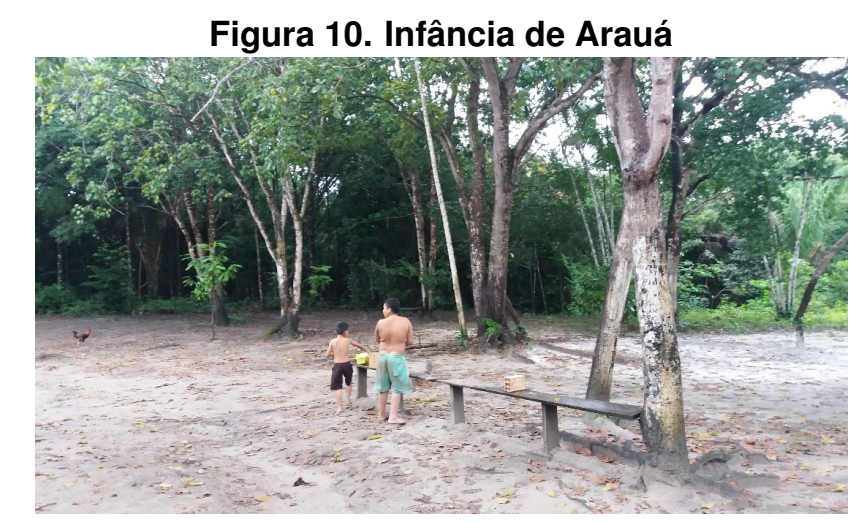

Fonte: Martins, 2019

Os brincares de crianças, as brincadeiras infantis no campo estão frequentemente ligadas aos elementos da natureza, com as quais elaboram uma série de conhecimento, aprendem a distinguir uma infinidade de planta, árvores, insetos e animais. Sua orientação espacial é desenvolvida a partir de referências próprias, imperceptíveis ou indistinguíveis a um observador da cidade.

Os interlocutores da pesquisa são quatro crianças na faixa etária entre seis e oito anos, elas estavam acompanhadas de dois adultos, mãe e avó, com características étnicas diferentes. As crianças se identificaram como sendo pardas e negras.

As crianças estão matriculadas na Escola da Comunidade de Arauá, frequentam o Ensino Fundamental. Na Comunidade elas realizam tarefas domésticas e ajudam no cuidado com os irmãos menores.

A pesquisa adotou a roda de conversa conforme orienta Souza (2014) sobre pesquisas com crianças. As rodas aconteceram no espaço de suas casas em companhia de um adulto. 
O roteiro da roda de conversa com as crianças teve o intuito de situar o contexto social e cultural delas, as suas experiências na fabricação do abano, as brincadeiras e a forma como se relacionam com a natureza. Ainda, buscou-se saber sentido da Escola em suas vidas.

\section{Crianças e o fabrico do abano na Comunidade de Aruá da Amazônia Bragantina}

Criança. [...] eu aprendi a fazer o peneiro com guarumã, o abano com palha do coqueiro, tudo isso eu aprendi olhando minha mãe deixava o paneiro e eu ia pegar aquela coisa e aí eu aprendi né. O abano também e eu ficam eu olhava a minha mãe ia cortar palha no mato, o olho do coqueiro pra fazer o abano e eu ficava olhando ela fazer o abano, quando ela deixava o abano, eu ia lá e aí eu pegava o abano e ia fazer né, eu acho tão bonito o abano e eu queria que os meus netinhos fizesse o abano e quando eu vou fazer eu chamo meus netinhos pra olhar né, foi assim que eu aprendi.

Para as crianças a fabricação do abano é carregado de um saber cultural como prática artesanal.

[...] Ah!... a gente corta o olho do coqueiro, é coco babaçu bota pra mochar, e espera uma hora e aí a gente faz [...] é vai logo fazer o abano espichando a palha; eu faço bem rapidinho o abano. Eu apendi fazer e aí eu penso deixar para meus filhos né, fazer o abano se eles quiserem né.

O abano tem um sentido amplo.

Há [...] o abano é uma coisa de abanar o fogo, feita da palha do coco babaçu, eu faço também com guarumã, é, eu faço.

Para as crianças existe um aprendizado em tudo o que é transmitido pelos pais sobre a fabricação do abano. Essa questão cultural mostra que os saberes são adquiridos de convívios familiares e repassados de geração para geração em via oral por meio da percepção de seus interlocutores, em construções epistemológicas de saberes.

Criança 7 anos. O abano, a gente abana o fogo e fica no fogão.

Criança 9 anos. Eu fico olhando a mamãe fazer o abano e aí ela deixa cair no chão a palha aí eu pego e vou fazer o abano.... a mais não acertei fazer o abano. (Criança 9 anos).

Criança 8 anos. O abano a vovó faz ao abano eu fico olhando ela fazer, ela pega assim. Faz assim [...] e aí ela faz o abano. 
Percebe-se na fala, o significado e participação social das crianças na pratica da fabricação do abano. As crianças se apropriam simbolicamente de seus significados da linguagem utilizada em cada contexto. $E$ assim manifestam suas experiências a respeito do uso e da fabricação do abano.

\section{CONSIDERAÇÕES FINAIS}

As análises o abano é um artefato cultural usado com frequência para abanar o fogo, manter acesso labaredas de fogão de barro, fabricado com palhas de coqueiros babaçu, retirada a matéria prima, para a fabrico do abano, utilizando apenas, parte mais nova ou olho, depois colocada a folha aberta ao sol por algumas horas e logo depois começam trançados em forma triangular até que esteja finalizado.

As crianças praticam os saberes culturais como atividade familiar e a mesma não interfere no processo escolar, principalmente, em fabricar o abano, por isso o estudo considera que elas atribuem um sentido a confecção do abano como um tempo de brincadeiras, uma vez que não se observou a obrigatoriedade da criança aprender a confecção do abano. De um total de cem crianças moradoras da Comunidade, as quatro participantes estão inseridas na fabricação do abano como atividade artesanal da sua família.

Por fim, a pesquisa revela sobre a transmissão do saber de criança na fabricação do abano em Arauá como fenômeno dos saberes tradicionais que devem fazer parte do currículo escolar, pois essas questões abordadas não estão inseridas no campo do currículo, nem fazem parte de um processo de ensino pela Etnomatemática, que deve ser aplicado no ensino da Matemática, da Língua Portuguesa, das Ciências, da História, ou seja, uma proposta curricular de ensino e aprendizagem pelo trabalho interdisciplinar voltado para a fabricação do abano.

\section{Referências}

Brasil. Decreto $\mathrm{n}^{\circ} \mathbf{6 . 0 4 0}$, de 7 de fevereiro. Institui a Política Nacional de Desenvolvimento Sustentável dos povos e comunidades Tradicionais. Disponível em: http:www.planalto.gov.br/ccivil03/ato20072010/2007/decreto/d6040.htm.acesso em11abr.2007.

DIEGUES, Antônio Carlos Santana. O mito moderno da natureza intocada. São Paulo Annablume/ HUCITE/ NUPAUB/USP P,2002. 
FRANCO, H. B., Artesanato Paraense: tradução e expressão de uma cultura, Belém, Nosso Pará, n.4, p.64-79, set.1997.

GEERTZ, Clifford. Uma descrição densa: por uma teoria interpretada da cultura. $\mathrm{N}^{\circ} \mathrm{a}$ interpretação das culturas. Rio de Janeiro: Zahar Editores, 1988, p. 13-44. SILVA. Ronaldo Ferreira da. Mapa da Comunidade do Arauá ? adaptado. 2019. (Redesenhando do MADAM).

SOUZA, A. P. V. Trabalho Infantil: Uma análise do discurso de crianças e de adolescentes da Amazônia paraense em condição de trabalho. 2014. $195 \mathrm{f}$. Tese de Doutorado em Educação- Universidade Federal do Pará, Ciências da Educação, Belém, 2014.

SOUZA, A. P. V. e. As infâncias de cá. FIPED, 2018 - Universidade Federal do Pará, Ciências da Educação, Abaetetuba, 2018.

TIBALLI, E. F. A; JORGE, L. E. A etnofotografia como meio de conhecimento no campo da educação. Revista Habitus, Goiânia, v. 5, n.1, p. 63-76, jan./jun. 2007.VELTHEM, L. H. A Pele de Tuluperê: uma etnografia dos trançados wayana. Belém: Museu Paraense Emílio Goeldi, 1998. 251 p. (Coleção Eduardo Galvão). 